\title{
Las causas del curanderismo según la prensa en Tandil y en Buenos Aires a principios del siglo XX
}

\author{
Causes of folk medicine according to the press in Tandil and \\ Buenos Aires at the beginning of the $20^{\text {th }}$ century
}

Astrid Dahhur astridahhur@gmail.com

http://orcid.org/0000-0001-6535-0819 Universidad Católica Argentina (Argentina)

\section{Resumen}

En este ensayo analizamos algunas notas periodísticas publicadas en revistas y periódicos de la ciudad de Buenos Aires y la ciudad de Tandil sobre la medicina popular. Buscamos visibilizar la importancia que tuvieron estas publicaciones como voceras de los médicos, políticos y ciudadanos letrados respecto de sus opiniones sobre la medicina popular y las consecuencias para la salud de la población.

Asimismo sus dichos permiten reconstruir en parte el estado sanitario de la población, así como las cuestiones culturales, económicas y sociales que permitían la existencia de médicos populares durante un periodo en el que se daba un proceso de medicalización en el territorio argentino. Como veremos, la prensa señalaba distintas razones por las que existían los llamados curanderos, sin embargo apuntaban directamente a la medicina como así también a la falta de educación de la población como responsables. 
Palabras clave: prensa; medicina popular; siglo xx; medicalización; Buenos Aires.

Abstract

In this essay we analyze some journalist notes about folk medicine published in some magazines and newspapers in the city of Buenos Aires and Tandil. The purpose of this work is to make visible how these publications became the voice of doctors, politicians and citizens educated about their opinions of folk medicine and its consequences for the population's health. In addition, their words allow recreate how was people's health, as well as cultural, economical and social factors which explain folk healer's existence during the medicalization process in Argentina. As we will demonstrate, the press mentioned several reasons for the presence of these healers; however she indicated medicine and the lack of education as responsible.

Keywords: press; folk-medicine; $20^{\text {th }}$ century; medicalization; Buenos Aires.

El siglo XIX con el higienismo -corriente que veía en las condiciones de vida el origen de las enfermedades- y el XX con la bacteriología -ciencia que estudia los gérmenes y el desarrollo de antibióticos- marcaron hitos en lo referente a los intentos de preservación de la salud de la población. Las discusiones que presentamos en este ensayo se enmarcan en un proceso de medicalización -forma en que el ámbito de la medicina moderna se ha expandido en los años recientes y abarca problemas que antes no estaban considerados como entidades médicas-. En los artículos periodísticos hallamos un discurso uniforme que plasmaba la preocupación por la salud de la población, tanto para las autoridades estatales como médicas. Asimismo, la prensa fue un mecanismo por el cual se dieron a conocer algunas de las críticas al estado sanitario, incluidos médicos y los médicos populares o como los llamaban, curanderos.

Es así que la medicina popular, cúmulo de prácticas y saberes médicos transmitidos de forma oral por fuera de las instituciones académicas, y sus agentes fueron perseguidos por diversos motivos, el más recurrente fue el del monopolio del arte de curar en todo el territorio nacional y, en nuestro caso en particular, en la provincia de Buenos Aires. El discurso oficial se centraba en la preocupación por la salud de la población, durante un periodo en el que se conjugaban cuestiones políticas, sociales, económicas e inmigratorias diferentes desde 1850 en adelante.

Entendemos que la prensa era, especialmente durante el siglo XX en la ciudad de Buenos Aires y en la ciudad de Tandil, un espacio público en el que se visibilizaban, se reflexionaba y 
se discutía sobre tópicos considerados de interés para la población (Kircher, 2014: 116). En este sentido, Julio Aróstegui (1995: 336) ha prevenido a los historiadores respecto del empleo de la prensa como fuente, dado que es una referencia parcial de la realidad, un producto sociocultural que responde a intereses y concepciones de los periodistas y líneas editoriales.

En este ensayo discutimos la idea que la medicina popular era concebida como la principal responsable de los problemas sanitarios como esgrimían los médicos. La prensa permite matizar la idea de los galenos que apuntaban a la medicina popular como el "gusano roedor", expresión acuñada por el médico y cirujano Manuel Montes de Oca (1854: 50).

En esta oportunidad nos proponemos visualizar algunos de los debates suscitados desde diarios de tirada masiva y publicaciones partidarias, sobre la medicina popular y sus causas. El hecho de emplear fuentes periodísticas de una ciudad capital y cosmopolita como Buenos Aires y la de una ciudad pequeña como Tandil demuestra que el problema de la salud y el ejercicio de la medicina no eran taxativos de las sociedades rurales y asiladas. Por el contrario, en las urbes debido a una serie de factores sociales, económicos y culturales este tipo de prácticas no eran infrecuentes y la prensa en ambos lugares se ocupaba de estos temas. Consideramos que la prensa no es sólo una representación sino también un actor activo en lo político, cultural y social, imponiendo temas de discusión. El empleo para el análisis de la medicina popular de publicaciones de una ciudad pequeña como una urbe más importante permite hallar preocupaciones en común en dos espacios geográficamente y socialmente distintos como otros estudios han demostrado (Rivero, Carbonetti y Rodríguez, 2017). Es así que la prensa, como señaló Mauro Vallejo (2017: 298), sería el escaparate en el que se visualizarían las disputas entre la medicina popular y la académica.

\section{La medicina popular y su propagación, causas según la prensa médica}

Desde la corporación médica con asiento en Buenos Aires, y particularmente la dependiente del agente sanitario nacional, se pueden apreciar las quejas y el malestar de algunos miembros que, aun durante el siglo XX, veían con ojos críticos el accionar de la población. Este fenómeno se dio también en la provincia de Córdoba durante el siglo XX (Rivero, Carbonetti y Rodríguez, 2017; Rivero y Valandía, 2018) en donde la medicina académica denunciaba mientras el periodismo, a través de los diarios, prestaba espacios publicitarios para estas personas. Estos agentes de la medicina popular han presentado fascinación y repulsa en igual medida para los periodistas y cronistas de las épocas que los han retratado favoreciendo los mitos (Márquez- 
Estrada, 2018: 85; Vallejo, 2017). La prensa, lejos de ser un observador objetivo, desde sus editoriales expresaba distintas líneas ideológicas buscando comprender y cambiar situaciones referidas al estado sanitario de la población. Sin embargo, de acuerdo a la situación y a la línea editorial, apoyaban el accionar de los médicos o los criticaban como así también apuntaban al espacio que ocupaba la medicina popular en un sistema de sanitario deficitario.

Asimismo, en los escritos se aprecian diversas cuestiones. La primera, la indignación por la existencia de estos personajes y por no poder encerrarlos o erradicarlos; entiéndase que en publicaciones constantes en los anales del Departamento Nacional de Higiene (DNH) para 1905 los médicos reclamaban por una legislación actualizada en el siglo XX, pues los mecanismos de castigo y regulación eran obsoletos. A esto debe sumársele la ineficiencia de las prácticas curativas de los médicos. $Y$ cómo las curas milagrosas, basadas en las capacidades extrasensoriales de los médicos populares, podían triunfar en donde la ciencia no había podido: "...muchos pacientes que han perdido la paciencia esperando una mejoría á sus dolencias en manos del médico, se dirijen allí donde se les garantiza la cura á ojo cerrado" (ADNH, enero de 1908: 14-15). La editorial del DNH continua criticando a la prensa pues "no cuesta mucho encontrar un anuncio que garantice esas curas".

Luego las personas,

al llegar á manos del curanderos, éste comienza con el tratamiento que profetiza, sea por la mano, por el aire, el agua, sea otros cualesquiera y en muchos casos la casualidad y la sujestión (sic) aminoran los síntomas más pronunciados, como el dolor, la coloración de la piel, etc.

La nota concluye con que si se da una curación o alivio "el paciente es verdadero portavoz y el mejor propagandista del curandero" (ADNH, enero de 1908: 14-15). Por curandero entendían a toda persona que curaba sin tener título de médico, por ello se consideraba que era imperante terminar con esas prácticas, pues podían ser perniciosas para la salud de la población.

Sobre la propagación, tres artículos periodísticos de orígenes disímiles apuntaban críticamente a la población consumidora de las prácticas de la medicina popular. Los dos primeros provenientes del diario El Eco de Tandil de 1900 acerca del curanderismo. A continuación empleamos la revista Germinal, dependiente del partido socialista de Tandil entre 1920 y 1930, cuando los temas por la salud de la población eran tópicos de discusión entre los pensadores de este partido. $Y$ finalmente analizamos a la prensa de la ciudad de Buenos Aires que se manifestaba en la década del veinte sobre el curanderismo. Como apreciaremos en estos 
artículos seleccionados la medicina popular no era la única culpable de los males que acuciaban a la sociedad.

\section{La prensa tandilense}

El Eco de Tandil a principios del siglo XX, en sintonía con las declaraciones en los Anales del $D N H$, cuestionaba a la medicina popular y buscaba hallar las causales de su existencia en la Argentina. Es así que el 23 de septiembre de 1900 publicó el artículo "Causas del curanderismo", en el cual el autor señaló tres causas: los malos médicos, el precio de los medicamentos y la ignorancia del vulgo. En la primera causa apuntaba directamente a la corporación médica, y al afán de los médicos nóveles por hacerse de un nombre y dinero en la campaña bonaerense:

se lanzan á la campaña á ejercer su profesión, y sin preocuparse de seguir estudiando solo ponen todo su afán en ganar dinero; de manera que si hacer un estudio detenido de la enfermedad del paciente y con solo sacar la lengua y tomarle el pulso recetan lo que creen benéfico según su conciencia, cuando sobre esta debiera primar la ciencia (El Eco de Tandil, 1900: 3).

Esto significaba para el observador que lo que les motivaba directamente era la codicia. Asimismo, se destacaba cómo la falta de un examen apropiado podía derivar en un diagnóstico errado y su consecuente tratamiento, siendo la muerte el resultado de una complicación innecesaria. Es en ese momento, según el periodista anónimo, en donde "se declara que la ciencia ha sido impotente para combatir el mal, cuando lo que ha sucedido es que no se ha sabido dar con la clase de dolencia”. El redactor de la nota, ante esto, apelaba al sarcasmo diciendo que como quien lo afirmaba poseía un título de médico su palabra era incuestionable. Lejos está la opinión de esta persona y del editor del diario de ver a la ciencia y sus representantes como omniscientes y omnipotentes, siendo sus actitudes contradictorias con su discurso. Ahora bien, otra de las razones es el desahucio de los médicos a los pacientes que, ante la desesperación, apelan a los sanadores populares siendo el resultado no siempre el deseado por la corporación, haciéndose ellos mismos mala publicidad:

la familia desesperada- pone al enfermo en manos de una curandera que con unas cuantas cataplasmas y dos ó tres brebajes, lo salva; no nos negaré que esto sucede con mucha 
frecuencia; y las gentes, que no necesitan mucho se aferran en la creencia de que los médicos son unos inservibles y solo es bueno el curanderismo (El Eco de Tandil, 1900: 3).

En relación a esto, el redactor de la nota, como segunda razón del auge del curanderismo, manifestaba el precio excesivo de los medicamentos, principalmente para aquellos de escaso poder económico: "como el precio de los medicamentos no tiene taza y sólo está librado al capricho o buena voluntad de sus expendedores, estos les ponen el precio que le parece, pero ¿y el pobre?"

Esta misma sería la razón por la cual los pobres acudirían a un curandero. Si bien esto no dejaba de ser cierto, el autor cae en la falacia de creer que sólo las personas de escasos recursos recurrían a los curanderos. Sin embargo, es entendible que buscase justificar el accionar de un sector poblacional escaso en recursos económicos e intelectuales. Esta última cuestión lo llevaría a señalar la "ignorancia del vulgo". Lo importante de este análisis, no exento de parcialidad, es mostrar las falencias del sistema sanitario y de la sociedad misma que, ante una serie de factores, decidían acudir a este tipo de personas que con sus prácticas ocupaban un espacio que la medicina académica no era capaz de atender. Es decir que desde la pequeña ciudad de Tandil se desautorizaba a través de la prensa los dichos de los mismos médicos que no asumían como uno de los factores de existencia de la medicina popular las limitaciones de la ciencia en ese momento como del acceso a la misma por parte de la población. En relación a esto último, en otra comunicación el mismo periódico alababa las grandezas de "Franklin, Volta, Edison, Flammarion, Koch y Charcot" aunque también hacía mención que las contribuciones de estos personajes no llegaban a toda la sociedad.

Continuaba criticando fuertemente el accionar de la sociedad que no se tomaba "el trabajo de combatir á los médicos del agua fría, á las curanderas y adivinas". Pero en una sintonía similar, no veía una desaparición pronta de este tipo de prácticas, pues no se las combatía desde el estado. La autocrítica es fuerte, pues apelaba a que se le hablara a la población claramente, advirtiéndoles que no oyeran: "á las patrañas y embustes de las adivinas: que es una solemne mentira su pretendido poder de adivinación". Sin embargo anteriormente manifestaba que brindaban un servicio que los médicos diplomados se negaban a prestar. Y claramente el periódico era quien señalaba las deficiencias en materia de salud y responsabilizaba al estado y la sociedad por permitir la presencia de los curanderos. En sintonía con este discurso, la prensa socialista de Tandil entre 1920 y 1933 se ocupó de la problemática de la salud, y también tocó el tema del curanderismo. 


\section{La ciencia y la medicina, estandartes del socialismo}

Las demandas del socialismo tenían como eje principal mejorar las condiciones de vida de los obreros. Su prédica rezaba por una promoción educativo-cultural y la elevación material del proletariado. Así, los socialistas argentinos retomaron estas directrices del socialismo internacional; enfatizando en la higiene, la salubridad y la vivienda (Barrancos, 1996: 178; Da Orden, 1991). Asimismo, actuaban en el contexto de una política sanitaria que tenía como intereses centrales el saneamiento ambiental y la lucha contra las endemias y epidemias en 1930. Durante esos años, se fue consolidando paralelamente un sector privado al cual acudían los grupos sociales de mayores recursos con capacidad de pago directo (Novick, 2008: 353).

Fue así que los males sociales, como el alcoholismo y las enfermedades venéreas derivadas de la prostitución, fueron motivo de preocupación de los médicos, varios de los cuales adscribían al socialismo, estructuras administrativas nacionales (Biernat, 2007: 257-258) para el tratamiento de las enfermedades venéreas. Entre ellos, algunos médicos socialistas como Ángel Mariano Jiménez, precursor del higienismo y político especializado en profilaxis, salud e higiene social. Algunos de sus trabajos guardaron relación con las problemáticas de la clase obrera acerca de la jornada laboral (Barrancos, 1996: 182). Sus posturas difirieron de algunos sectores conservadores como se ve en los enfrentamientos parlamentarios entre Eliseo Cantón y Enrique Dickman (Souza-Huarpe, 2008: 247-248) sobre el futuro Hospital de Clínicas. Analizaremos ahora algunas de estas nociones en un espacio geográfico diferente como lo era la ciudad de Tandil. Decidimos utilizar esta revista partidaria de la ciudad de Tandil como ejemplo de una línea de pensamiento que no coincidía con la de los médicos de la ciudad de Buenos Aires que no realizaban un mea culpa sobre su propias limitaciones y miserias al momento de salvaguardar la salud de la población.

Cabe destacar que Germinal, más allá de su sesgo claramente socialista visible en sus editoriales políticas y las referidas a la salud, no era el órgano oficial difusor del Partido socialista, aunque sus fundadores y editores fuesen miembros de esta agrupación, como eran los casos de Juan Nigro y su hermano. Sin embargo, difundía las ideas del partido socialista de Tandil, en especial, la voz de Nigro. Comparado con El Eco de Tandil de aquellos años, fue un diario mucho más político, aunque a su vez, abordaba diferentes temas que hacían al interés general. La salud de la población era una cuestión política.

Las editoriales eran combativas y cuestionaban continuamente a la política local, tildando a los funcionarios en ciertos momentos de inútiles e incompetentes. La tesis de Luciano Barandarián (2004: 75) quien analizó al socialismo desde sus orígenes hasta 1943 en la ciudad de Tandil, 
nos ofrece una mirada de los cambios en la estrategia del socialismo y del juego político tandilense, pero no se sumerge en los aspectos que nos conciernen y que motivaron este trabajo, es decir la salud y las prácticas de la medicina en general. La segunda época de Germinal (desde 1929 hasta su clausura, en 1943) fue una publicación que retomaba las directrices y las ideas del partido a nivel nacional, como lo atestiguaban las editoriales en las que reproducía discursos, ideas, fragmentos de libros y demás redacciones sobre y de Juan $\mathrm{B}$. Justo (Germinal, 9 de enero de 1929, p. 5), Nicolás Repetto y otros socialistas de renombre. Así, conforme nos adentramos en los años treinta y nos acercamos a los cuarenta, puede apreciarse una mayor preocupación por parte de esta publicación sobre la cuestión sanitaria de la comuna, que seguía las líneas a nivel nacional y provincial.

Las notas acerca de la medicina popular no aparecieron con mucha asiduidad en la prensa tandilense de los años treinta del siglo XX, pero por lo menos en tres oportunidades los periodistas se hicieron eco de su práctica en la ciudad de Tandil. Estas cuestiones como señalaron otros investigadores (Rivero, Carbonetti y Rodríguez, 2017: 24) son atravesadas por las líneas editoriales de cada medio publicado. La prensa de Tandil, en este caso, expresaba la preocupación de sectores políticos y sociales disímiles sobre la salud de la población y especialmente lo relacionado con la medicina popular. En este sentido encontramos cerca de seis editoriales que apuntaban a prácticas de medicina doméstica. Esto es interesante porque se apreciaba una separación entre el llamado curanderismo y algunas prácticas y remedios populares englobados dentro de la categoría "remedios caseros o domésticos". Esto pudo haber ocurrido debido a la existencia de ciertos avales por parte de la comunidad médica a ciertas prácticas populares, que fueron demostradas científicamente como válidas. Por otro lado, existían remedios que la medicina casera destacaba como propios, pero a su vez eran empleados por la medicina académica.

Es así que en la Página del Hogar, sección de la revista Germinal, encontramos menciones y consejos para poder paliar o curar ciertas enfermedades. Una de ellas era la seborrea; en esta oportunidad la descripción desarrollada sobre la etiología de la misma era firmada por un médico apellidado Schultz. La forma de combatir esta enfermedad capilar era mojando copiosamente el cabello con aceite y posteriormente lavarla con abundante agua y jabón. E inclusive explicaba el procedimiento en un caso extremo: "Si la capa de costra es espesa, desde que se termina la impregnación con el aceite se coloca en la cabeza del niño un gorro de franela, también empapado en aceite" (1).

A pesar de los consejos de médicos en las páginas de Germinal y del avance de la medicina en varios sectores de la sociedad, las prácticas del curanderismo aún imperaban en el Tandil de 
los años treinta como mostraba la prensa. En el número 5 del 6 de febrero de 1929, aparecía una nota en la página 7 bajo el título "El auge del curanderismo". Pero no sería la única de este tipo; por lo menos hemos encontrado dos menciones más en el periodo 1929-1933. Aparentemente no pasaba un día sin que la sociedad a través de la prensa tomara conocimiento del "constante y pernicioso incremento del curanderismo." El escritor veía las razones en la ignorancia de las personas que acudían a los sanadores, y advertía el escaso control que aplicaban las autoridades a la práctica de la medicina. Sus argumentos, en lo referente a este último tema, se basaban en unos panfletos que circulaban en la vía pública, uno de los cuales era reproducido:

\footnotetext{
Espiritismo y magnetismo. A los enfermos: Sea cual sea su enfermedad consultadme, sin perder tiempo, que con las nuevas y perfeccionadas aplicaciones de la Radioterapia...

Miles de enfermos han recuperado su salud por medio de este maravilloso sistema (...) Los que padeceis de males, daños, los que quieran adelantar en su negocio, los que quieran ser amados deben visitar al célebre Profesor Roberts recién llegado de Europa (Germinal, 6 de febrero de 1929, p. 7).
}

Nuevamente en el número 29 de la publicación los editores censuraban varias de las prácticas que llevaban a cabo "Ios embaucadores", que resolvían los problemas de la vida gracias a la "ingenuidad de la gente". De acuerdo a la publicación, las personas que acudían a estos personajes eran quienes habían sido desahuciados por los médicos y que veían con ojos esperanzados las soluciones mágicas que se les ofrecían. Parte de la culpa según la prensa recaía sobre la corporación médica, que no brindaba la atención requerida a los pacientes.

El "charlatanismo", como lo llamaban los socialistas, no era frenado por el DNH ni por los círculos médicos; encontraban explicación a esto en la existencia de una convivencia entre el poder político -algo que trataremos posteriormente con el caso de María de Turdera- y estas gentes. Asimismo para justificar la consulta por parte de la población hallaban en la educación y en la poca predisposición que tenía "nuestro pueblo" a ella el motivo de la existencia de "los embaucadores", que vivían de la ingenuidad de las personas.

Como reacción a este artículo redactado por A. Aguilar, vela en el número 31, con su escrito "Anhelos Culturales", señalaba que "la mayoría del pueblo que, por desgracia, admite sin análisis previo cuanta superstición existe en la vida". La solución que brindaba para este problema cultural era la fundación de bibliotecas, ya fuesen populares, de partidos políticos y demás instituciones. Estas nuevas y las ya existentes deberían generar ciclos de conferencias y actividades destinadas a eliminar la "superstición" y fomentar la cultura. A pesar de las 
críticas a la medicina igualmente para los editores de Germinal siempre era preferible la atención de un médico diplomado. Por ejemplo al publicar una nota sobre el cáncer (Germinal, 14 de mayo de 1930, p. 3) se recomendaba: "No se deje aconsejar por personas profanas a la medicina, que le harán perder tiempo y la curación. Cuidese de los charlatanes y de los que prometen curaciones con remedios no sancionados por la ciencia".

Un tratamiento incorrecto de las dolencias podía derivar en la muerte de los pacientes, pero esto no sólo era inherente a las prácticas de los sanadores populares sino también a la de los médicos diplomados: "Que causas han provocado tan doloroso suceso? Inasistencia médica? Falta de medicamentos? Desatención del facultativo que intervino?" (Germinal, 11 de septiembre de 1929, p. 1). Estas eran las preguntas en una nota titulada "La tragedia de los pobres", en la que se daba cuenta de las muertes en dos familias de sus hijos por una enfermedad. No se daban mayores detalles, pero pudo haber sido una enfermedad infectocontagiosa o una intoxicación. Pero, el motivo intrínseco de la nota radicaba en la crítica a la atención médica en Tandil generando, en nuestra opinión, la consulta a otros conocedores de las artes curativas no avalados por el estado.

Así, los editores de Germinal, en la nota titulada "El auge del curanderismo", acusaban directamente a los médicos de las consecuencias aparejadas por la práctica ilegal de la medicina. En principio, el relato comenzaba con el horror, y en nuestra opinión vergüenza, ante la existencia y continua reproducción de "curalotodos y manosantas". Se señalaba a los mismos como los autores de muertes por sus tratamientos. En esta oportunidad se acusaba a una mujer que oficiaba de partera, aparentemente sin el título pertinente, de ser la responsable de la muerte de tres parturientas. Aunque la acusación más grave era que esta supuesta partera trabajaba en "connilencia (2) (sic) con ciertos médicos, o que por lo menos estos se prestan a sacarla de apuros cuando comete una barrabasada, diagnosticando cualquier enfermedad a fin de relevarla de cualquier responsabilidad" (Germinal, 25 de diciembre de 1929, p. 1).

Si bien se aclaraba que este era un rumor, se instaba al Círculo Médico de Tandil a que se pronunciase al respecto y que tomase medidas para evitar casos similares en el futuro.

Paralelamente a estas acusaciones, desde la sección la Página del Hogar se daban a conocer o se recordaban algunas de las propiedades medicinales de la miel, remedio casero de variadas enfermedades. Dentro de las bondades de este producto apícola se encontraban su utilidad para el insomnio, la "debilidad del estómago"; era a su vez un eficaz antídoto para dejar de fumar, siendo el tabaquismo censurado como ya hemos mencionado. Pero, lo más llamativo era la convicción de que la miel mezclada con tomillo podía curar la tos convulsa, una afección 
compleja que era imposible de sanar tan sólo con esos dos elementos, dado su origen bacteriano. La miel también era recomendada como un excelente alimento para los pequeños al ser azúcar natural (Germinal, 1 de abril de 1931, p. 2) y por lo tanto los proveía de un elemento necesario para su crecimiento sin demasiada elaboración. Tampoco se olvidaba resaltar las bondades de este producto en lo referente a gripes y afecciones de las vías respiratorias, recalcándose siempre su uso continuo en las preparaciones farmacéuticas (Germinal, 1 de abril de 1931, p. 2).

Desde el socialismo se abogaba por una medicina accesible a toda la población, para ello era imprescindible el correcto funcionamiento de las instituciones encargadas de ello. El tema básicamente era una cuestión de educación, sin embargo los casos que se daban en la ciudad de Buenos Aires desautorizaban esta hipótesis.

\section{Una mirada porteña del problema}

A modo de refutación de la idea de que sólo las personas carentes de instrucción eran quienes acudían a los curanderos Roberto Arlt, en una comunicación telefónica ficcionada con un médico indignado, relataba las palabras del galeno: "en estos momentos, mi señora está terminando de vestirse para ir a consultar a un curandero" (Arlt, 1993: 39). Su mayor estupor radicaba en que él la había diagnosticado y explicado el motivo por el cual su condición no mejoraba: "ir a lo de un desvergonzado, que se las da de naturalista, con el objeto de que le adivine qué enfermedad padece, la cual, entre paréntesis, consiste en unas eczemas, naturalmente duras de curar, debido a que es diabética" (Ídem).

Las palabras del médico eran de espanto al describir la práctica curativa consistente en el análisis de la letra y el nombre del paciente; para el médico el problema radicaba en la simpleza de su mujer que caía en un embauco. Agregaba en su descargo ante Arlt que vivía en Villa Domínico, y no cobraba la consulta. Sin embargo recetaba "yuyitos que un cómplice suyo, en la herboristería de la esquina, vende a peso de oro" (Ídem). La descripción es la de un timo que a gran escala redituaba ganancias para él y su cómplice. Lamentablemente el relato novelado no se extiende en mayores detalles, salvo por la reflexión del periodista que ve al público femenino como susceptible por su propia naturaleza a creer en los dichos de personajes como estos. Este continúa con una serie de comentarios entre el reportero y el médico sobre la naturaleza de las mujeres y lo volátil de su pensamiento y cómo las propias cuestiones hormonales del sexo femenino propiciaban que creyesen en estos personajes: 
"hasta las mujeres de los médicos tienen aserrín en el cerebro". El problema aparentemente eran las mujeres que por su propia naturaleza se convertían en la presa de estos embaucadores según el indignado médico: "Las necias se mueren por los charlatanes. Como las necias abundan, el problema del hombre inteligente es mucho más grave de lo que puede suponerse. Los charlatanes son los únicos individuos que acaparan la atención de las frívolas y mentecatas" (Arlt, 1993: 39). Apelaba en su alocución a la necesidad de creer en lo imposible y los milagros de parte de un sector de la población, por lo que, para este profesional de la salud: «Él me va a curar». «Él me va a mandar a Jolibud». «Él hará que yo supere a Berta Singerman». Sin embargo, a través de este cuento, lo que se esconde en verdad es el profundo malestar de la corporación médica al fracaso que representa su rol en la sociedad. Sumado a esto la cólera, el enojo del profesional por el tiempo invertido para prepararse como médico, unos siete años sin contar el bachillerato, es decir dinero y tiempo invertidos y que personajes sin titulación prometiendo curas milagrosas o los secretos del éxito sin ningún respaldo científico. En este sentido Arlt se convirtió mediante su escrito en la voz del médico indignado que veía como su esposa, una mujer educada, caía en los "engaños" manifestados. A diferencia de los artículos de la prensa tandilense vemos un apoyo a la corporación médica y una crítica a la llamada medicina popular.

Empero, esta narración manifiesta en verdad el fracaso de la medicalización y de la educación de la población en materia sanitaria y el resabio de prácticas y creencias que, para ciertos sectores intelectuales, no eran más que meros actos folclóricos lejanos que debían ser recolectados y preservados como propios de la tradición. En los artículos anteriores, la credulidad básicamente era patrimonio de las personas que carecían de recursos intelectuales. Sin embargo, el caso de María de Turdera, una curandera con gran repercusión, tanto en la ciudad de Buenos Aires como las localidades linderas, rompía con este molde.

Hacia las primeras décadas del siglo XX, desde la criminología y la psiquiatría se buscaba combatir a los curanderos esgrimiendo el argumento de que sufrían varios de ellos neurosis místicas, que les hacían creer que poseían poderes sobrenaturales para curar a los demás y por ende eran peligrosos para ellos mismos y terceros. En otras palabras, se convirtieron en pacientes. Un ejemplo se dio a principios del siglo XX fue el de la Madre María de Turdera, quien en 1903 fue sometida a peritajes y se concluyó que poseía un delirio místico que la hacía creer poseer capacidades divinas para curar personas. Este caso resultaba emblemático para la neurosis histérica producto de una herencia degenerada. Los psiquiatras responsables de las pericias fueron los doctores Alba Carreras y Acuña, quienes lo hicieron a pedido de la justicia porteña. Más allá del elemento útil que resultaba la psiquiatría para el control del 
ejercicio ilegal de la medicina, el cambio de concepción respecto de los curanderos desde la medicina dio un giro de ciento ochenta grados. Si en principio eran competidores, poseedores de un conocimiento que podía ser útil basado en los años de empiria, o meras supersticiones arquetípicas de sociedades atrasadas, directamente a principios del XX pasaron a ser considerados enfermos mentales que necesitaban de los servicios y cuidados de la medicina académica.

Así, la psiquiatría sería la rama de la medicina encargada de hacer frente a los curanderos y catalogarlos como enfermos en las primeras décadas del siglo XX. La Madre María fue uno de estos casos. Tras su muerte, tres periódicos porteños se hicieron eco de su vida y funeral: La Razón, Crítica y La Nación. Las tres líneas editoriales daban su parecer acerca de un problema de índole social como lo era el curanderismo. En estos tres artículos periodísticos lo que se aprecia no es una crítica a la curandera en sí, sino a la sociedad y los sectores acomodados que la frecuentaban.

La Razón, considerado uno de los periódicos populares de la ciudad de Buenos Aires, detallaba la clientela de María con sarcasmo e ironía:

\footnotetext{
Clientela inmensa: fue también clientela distinguida. No fue la Madre María la vulgar adivina de la calle Rincón.

Los automóviles particulares parados frente a su casa, la cantidad de personas de provincia y aun hasta de Montevideo que venían a consultarla (La Razón, 5 de octubre de 1928, p. 5).
}

Estas dos frases desautorizaban todas aquellas creencias de la época que señalaban a los clientes de los curanderos como personas de bajos recursos y carentes de educación e instrucción. Por el contrario, hemos encontrado testimonios en los cuales se aseveraba que Yrigoyen, Roca y Juarez Celman, entre otros, la visitaban. La idea de que sólo los sectores populares eran quienes acudían a los sanadores populares era desestimada por este periodista. Para comprender el fenómeno que causaba la madre María deben contemplarse tres factores:

1. El fuerte misticismo y religiosidad que rodeaba a la Madre María atraía a personas con una fuerte creencia religiosa.

2. La ciencia y la medicina actuales podían ser deficitarias para ciertos males que requerían un tratamiento diferente al desarrollado por aquellos años

3. La tradición popular de los criollos como así también de los inmigrantes contemplaban y daban lugar a que desarrollasen su actividad los sanadores populares. 
El periodista representaba también a la Madre María como una mujer completamente diferente de otras de su propio gremio. Si bien la ironía era la protagonista en sus frases, no puede descartarse abruptamente la diferenciación que el periodista realizó entre María de Turdera y las demás mujeres de su misma profesión, pues no empleaba el tarot ni el globo de cristal o practicaba la quiromancia. Sus visiones eran naturales por lo que "mantuvo su rango superior", siendo "de más elevada alcurnia dentro del gremio" (La Razón, 5 de octubre de 1928, p. 5). La crítica a su accionar era invariable, aunque su arte era considerado más refinado que el de otras adivinas; aquí no se la denominaba ni sanadora o curandera. El motivo de esta calificación era su consabida capacidad para la predicción de acontecimientos (Bubello, 2010: 117-118). El hecho que no necesitase de trucos u objetos para llevar a cabo su labor podía generarle un ápice de simpatía por parte del escritor de la nota. Sin embargo, esto no eclipsaba la crítica mordaz al accionar de todos aquellos que explotaban la credulidad propia de los ignorantes. Las palabras del periodista tenían puntos de contacto con la prédica científica que, desde hacía más de setenta años intentaba desarraigar lo que consideraban la práctica ilegal de la medicina, tanto en el ámbito rural como citadino.

Crítica, por su parte, que paradójicamente poseía una sección de ocultismo, se preguntaba sobre el nivel de cultura del pueblo argentino a raíz de los funerales de María de Turdera. El redactor entendía que, de existir un grado de cultura, personas de diferentes extracciones sociales no acudirían a un médico popular: “¿Somos en realidad un pueblo culto? ¿Hasta dónde marchamos al compás de los países civilizados? ¿Sigue siendo Buenos Aires la gran aldea de hace cien años?" (Crítica, 5 de octubre de 1928, p. 5). La alusión a la novela La Gran Aldea de Lucio Vicente López (4), llevó al periodista a reflexionar si el progreso y la ciencia habían triunfado. La ciencia no logró desterrar la superstición, como así tampoco la educación fallida, que era incapaz de destruir las creencias populares e instaurar la razón. Su relato generaba la impresión que desde la caída de Rosas todo fue un espejismo.

Al igual que La Razón, Crítica desmitificó la relación ignorancia-pobreza-curanderos. Este diario reiteró el eclecticismo de la clientela de la Madre María. Su muerte y la procesión que generó su velatorio hicieron reflexionar al periodista sobre las creencias y costumbres de la población. La verdadera crítica, entendemos, residió en la imposibilidad por parte del Estado (quien no hizo nada de acuerdo al redactor con la práctica ilegal de la medicina) para poner fin a la actividad de María y de tantos otros detrás de ella. Esto era confirmado por La Nación: "Roca le obsequió una casa, el conquistador del desierto, dos veces Presidente de la Nación 
(...) La Madre María frecuentaba las tertulias de Juárez Celman, Pellegrini, Mitre, Alsina, Yrigoyen" (La Nación, 5 de octubre de 1928, p. 6).

Como diario popular, Crítica explotaba la comercialización de las llamadas supersticiones; la sección de ocultismo era prueba de ello. María exponía a la luz la ineficiencia de la corporación médica por hacerse del control del ejercicio de la medicina. Pero, también se hallaba presente el ataque a una educación que no había logrado desarraigar las prácticas de la medicina popular.

En cambio, las palabras del cronista de La Nación destilaban una cierta admiración ante la Madre María: visitada y recibida por ilustres personajes de la política argentina, respetada, miembro de la sociedad porteña, María logró ganarse un lugar de reconocimiento en la población rioplatense. "Hacía milagros, en efecto. (...) Elevaba plegarias compuestas de palabras simples, imponía las manos a los necesitados de alivio, prescribía oraciones que no estaban en los devocionarios, daba consejos con voz límpida" (La Nación, 5 de octubre de 1928, p. 6).

Las alusiones a los milagros podían remitir a dos cuestiones. En primer lugar, el milagro podía devolver la fe a quienes la habían perdido, a los desahuciados por la medicina. Este podía consistir en que creyesen otra vez. En segundo lugar, el milagro podía residir en una cura llamada racionalmente inexplicable para los observadores de la época; hoy en día podríamos afirmar que varias de las enfermedades que sanaba factiblemente fuesen malestares somáticos.

Este extracto brinda una información más detallada del mecanismo empleado por María de Turdera durante la atención a los enfermos que el de los dos diarios anteriores. Se destacan los rezos pero también la unción de los enfermos con agua y aceite, símbolos de los sacramentos católicos. Las analogías no pueden pasar desapercibidas y creemos, aunque no podemos asegurarlo, que la Iglesia Católica no estaría conforme con el empleo de dos símbolos de la religión católica. Tanto el agua como el aceite purificaban y protegían, ambos han sido usados no sólo por esta creencia sino también por personas que practicaban tanto la magia blanca como la negra.

Acaso valía en ella más lo que decía y la manera de decirlo que lo que hacía. La gente hallaba en la elemental taumaturgia de la Madre María lo que la ciencia no puede ofrecer y la religión se niega a dar (La Nación, 5 de octubre de 1928, p. 6).

Juzgamos que estas dos últimas frases encierran la verdadera naturaleza de la popularidad: su accionar daba a sus pacientes todo aquello que la religión se negaba a dar y la ciencia carecía 
de herramientas para ello. Podemos entender que la inexistencia de una crítica mordaz en un diario menos "popular" que los dos anteriores hacia la Madre María tenía que ver con un llamado de atención a dos corporaciones que velaban por la salud de la población.

Los tres periódicos en este caso demuestran que la opinión pública buscaba imponer a la ciencia como autoridad en materia de salud. Aunque señalaban con precisión los motivos por los cuales, hasta el momento, esto había sido imposible; desde factores culturales hasta económicos y políticos. La prensa funcionó como mecanismo de difusión de ideas y críticas a los sectores encargados de garantizar el bienestar de la población y matizó la idea de que la medicina popular era la raíz de todas las enfermedades sino que una cuota de responsabilidad les cabía a las autoridades estatales y a los mismos médicos.

\section{Reflexiones finales}

A lo largo de estas páginas apelamos a la prensa para discernir las causas de la medicina popular. A través del análisis de las distintas fuentes documentales hallamos distintas posturas dentro de la prensa. Si bien el objetivo era concientizar sobre los peligros de la medicina popular para la población, lejos se hallaban los periodistas y editores de ser magnánimos con la academia médica. Esta se defendía apelando a la credulidad de quienes consumían las prácticas de la medicina popular, sin embargo no eran capaces de apreciar las deficiencias en materia sanitaria que empujaban a la población a los sanadores populares. Como así tampoco en sus dichos se contemplaba el componente cultural, sólo se lo asimilaba a un cúmulo de supersticiones. Por otro lado, la prensa vernácula sí apuntaba a la medicina académica como responsable, por lo menos en parte, de la existencia de curanderos, adivinas y otros tipos de sanadores. Las críticas a los médicos residían en los precios de sus honorarios, lo difícil de acceder a la medicación por cuestiones económicas como así también la falta de facultativos o el abandono de estos a sus pacientes. Estos factores pedestres junto con los culturales, más difíciles de desarraigar, aparecen en estos testimonios de época permitiéndonos contribuir para comprender un poco más como fue el proceso de medicalización en la provincia de Buenos Aires y en la ciudad de Buenos Aires. La prensa como actor político y cultural en las dos ciudades fue la encargada, desde sus puntos de vista, de matizar el éxito de la medicalización y de señalar a la medicina y autoridades estatales como responsables también de la existencia de la medicina popular. 


\section{Notas}

(1) Germinal, 23 de enero de 1929, p. 5.

(2) Pensamos que la palabra era convivencia pero por un error tipográfico en la imprenta se imprimió conninencia.

(3) Novela corta de Lucio Vicente López que narra los cambios producidos en la ciudad de Buenos Aires gracias a la inmigración ultramarina e interna y la bonanza económica de fines del siglo XIX, cambiando su fisonomía y las relaciones interpersonales.

\section{Fuentes consultadas}

Crítica (5 de octubre de 1928).

El Eco de Tandil (23 de septiembre de 1900).

Germinal (9 de enero de 1929).

Germinal (23 de enero de 1929).

Germinal (6 de febrero de 1929).

Germinal (11 de septiembre de 1929).

Germinal (25 de diciembre de 1929).

Germinal (14 de mayo de 1930).

Germinal (1 de abril de 1931).

La Nación (5 de octubre de 1928).

La Razón (5 de octubre de 1928).

\section{Bibliografía}

Alba Carreras, J. y Acuña, N. (1903). Curanderismo y locura. El caso de la 'Hermana María'. Archivos de Criminología, pp. 649-653.

Anales Departamento Nacional de Higiene (ADNH) (marzo-abril 1915). XII(2). Buenos Aires: Oficina Sanitaria Argentina.

Arlt, R. (1998). Aguas Fuertes Porteñas. Buenos Aires: Biblioteca Página 12.

Barandiaran, L. O. (2004). Sembrando ideas en la piedra. Los socialistas tandilenses, 19121946. (Tesis de licenciatura en Historia). Departamento de Historia Facultad de 
Ciencias Humanas, Universidad Nacional del Centro de la provincia de Buenos Aires, Tandil.

Barrancos, D. (1996). La escena iluminada. Buenos Aires: Plus Ultra.

Biernat, C. (2007). Médicos, especialistas, políticos y funcionarios en la organización centralizada de la profilaxis de las enfermedades venéreas en la Argentina (19301954). Anuario de estudios americanos, 64(1), 257-288.

Bubello, J. P. (2010). Historia del esoterismo en la Argentina: Prácticas, representaciones y persecuciones de curanderos, espiritistas, astrólogos y otros esoteristas. Buenos Aires: Ed. Biblos.

Da Orden, M. L. (1991). Los socialistas en el poder. Higienismo, consumo y cultura popular: continuidad y cambio en las intendencias de Mar del Plata. 1920-1929. Anuario del IEHS, 6(6), 267-282.

Huertas, R. (2009). Medicina social, control social y políticas del cuerpo. La subjetivación de la norma. En Miranda, M. y Sierra, Á. Cuerpo, biopolítica y control social: América Latina y Europa en los siglos XIX y XX. Buenos Aires: Siglo XXI.

Kircher, M. (2014). La prensa escrita: actor social y político, espacio de producción cultural y fuente de información histórica. Revista de Historia, 10, 115-122.

Novick, S. (2008). Población y Estado en Argentina de 1930 a 1943. Análisis de los discursos de algunos actores sociales: industriales, militares, obreros y profesionales de la salud. Estudios demográficos y urbanos, 333-373.

Rivero, D. y Vanadía, L. (2018). En los márgenes de la biomedicina: perspectivas en torno a la práctica ilegal de la medicina en Córdoba y Buenos Aires, 1920-1930. Trashumante: Revista Americana de Historia Social, 11, 98-121.

Rivero, M. D.; Carbonetti, A. y Rodríguez, M. L. (2017). Diplomat/certified knowledge alternatives in the public scene: an approximation to the quackery from the written press of the cities of Córdoba and Buenos Aires, Argentina in the 1920s. Revista Historia $y$ Sociedad, 33, 19-43.

Souza, P. \& Hurtado, D. (2008). Los «diputados médicos»: clínica y política en la disputa por los recursos públicos en Buenos Aires (1906-1917). Asclepio, 60(2), 233-260.

Vallejo, G. (2007). Males y remedios de la ciudad moderna: perspectivas ambientales de la eugenesia argentina de entreguerras. Asclepio, 59(1), 203-238.

Vallejo, M. (2017). El papel de la prensa en la lucha contra la consolidación de la profesión médica en Buenos Aires, 1890-1900. Dynamis, 37(2), 295-316. Recuperado de https://bit.ly/2ySyOOY 
Astrid Dahhur. Las causas del curanderismo según la prensa en Tandil y en Buenos Aires a principios del siglo XX 